\title{
MODELING AND ANALYSIS OF OUTER SHELL OF CRUISE MISSILE
}

\author{
Manikonda Ganesh ${ }^{1}$, Chittiprolu Nandini' ${ }^{2}$, Manyam Rakesh Reddy ${ }^{3}$, Boga Siva Kumar ${ }^{4}$, \\ Morampudi Chaitanya ${ }^{5}$ \\ ${ }^{I}$ Assistant Professor, Department of Aeronautical Engineering, MLRIT College, Telangana, India. \\ ${ }^{2}$ Student, Department of Aeronautical Engineering, MLRIT College, Telangana, India. \\ ${ }^{3}$ Student, Department of Aeronautical Engineering, MLRIT College, Telangana, India. \\ ${ }^{4}$ Student, Department of Aeronautical Engineering, MLRIT College, Telangana, India \\ ${ }^{5}$ Student, Department of Aeronautical Engineering, MLRIT College, Telangana, India.
}

\begin{abstract}
The advent of the modern cruise missile, with less radar detection and the ability to fly at low altitudes in sub sonic speeds with precise navigation, placed an extensive liability on all weapon systems in defence.The purpose of this project is to present a preliminary analysis and design of a cruise missile which fulfill the mission requirements. This design project comprises the concept exploration and development stages of the full design process. While designing we should take dimensions as per our requirements and should have tolerances to design parts. CATIA V5 is used as design tool. The inlet temperature, pressure, density and altitude are the parameters to analyze the flow properties. The analysis done in the ANSYS WORKBENCH 14.5.This paper discuss the flow of the designed model. In this paper we are going to discuss key aspects in aerodynamics of wing and fin.
\end{abstract}

Keywords: Wing, Fin, Pressure, Density, Altitude, Aerodynamics

\section{INTRODUCTION}

Missile is a word taken from the Latin word called "mittere". It is self guided or propelled system, that is used to target an object. The guidance system was advent in 1930s and the word came into existence after world war II[1]. the history of missiles begins with the World War I with the use of V1 and V2 missiles by Germany .Germany's V-2s falling on London in 1944-1945, generally referred to as rocket. Missiles are commonly powered by rocket motors, but in present it is also powered with air breathing engines. Cruise missiles, invented in the 1940s and enormously used since 1980s. The target, by using its energy sources of reasoning may escapes the missile by moving either to the Left, right, top or bottom according to the trajectory or path of the missile. In this case, missile has been failed in its intention of hitting the target[2][3]. Missiles have four system components: targeting and/or missile guidance, flight system, engine, and warhead.

\subsection{Classes of Missile}

The classification of missiles generally based on range, launch mode, guidance system, aerodynamic control adoption, type of trajectory, propulsion system but now classification is based on the method of launch mode and related trajectories are showed in Fig 1.

1. Surface-to-surface-missiles (SSM),

2. Surface-to-air missiles (SAM),

3. Air-to-air missiles (AAM), and

4. Air-to-surface missiles (ASM).

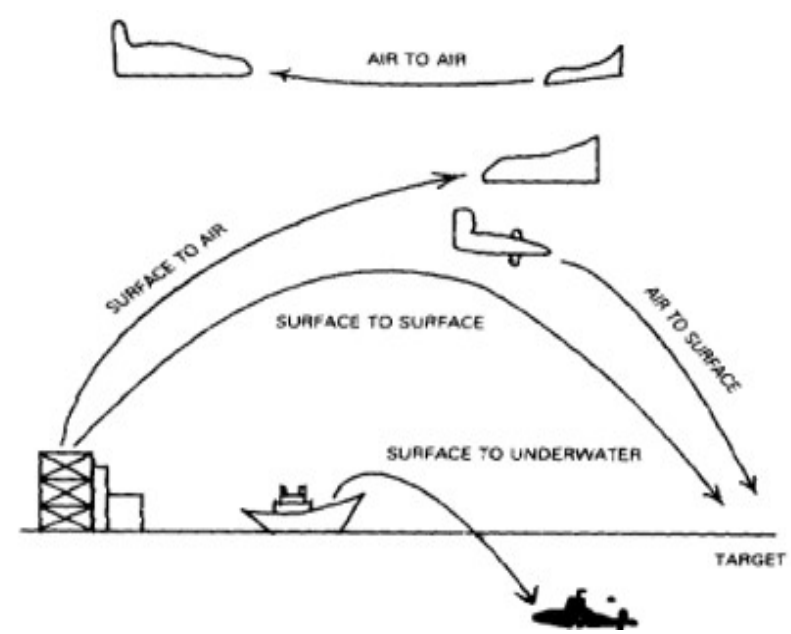

Figure 1: Type of missile by method of trajectory

\section{LITERATURE SURVEY}

Preliminary design and analysis of Ram jet missile: This was explained by the Department of engineering research and development, university of Michigan. They said that the purpose of this report is to present a preliminary analysis and design of a missile which fulfills the requirements specified by Project MX - 794 as outline in the University of Michigan. UXR -8 for the UMA - 1 missile and which runs with the ram jet propulsion for the major portion of its thrust. Final dimensional and weight data are to be compared for equal end condition of altitude, horizontal distance and time, to model UMA - 1 liquid rocket missile. Initial weight and overall length of the ram jet missile are considerably lower than that of the liquid rocket missile for identical interception conditions, and are due preliminary to the extremely high specific impulse of the ram jet. 
Design of a Tomahawk Cruise Missile Booster Rocket Motor: Tomahawk cruise missile booster motor was introduced by Devon K. Cowles,as an Engineering thesis to the Graduate Faculty of Rensselaer Polytechnic Institute. This project aims to design a ground launched rocket booster which meets given specific mission requirements. The mission restrictions include maximum flight altitude ,minimum speed, minimum length and weight. The mission is to launched with a 3,000 $\mathrm{lb}$ payload like Tomahawk cruise missile which can reach an altitude of 1,000 feet with accelerate capacity of the missile to $550 \mathrm{MPH}$ (807 fps). To reach the given requirements the weight of the body must be very light with required reliability \& structural integrity.

Engineering design hand of research and development of material for Ballistic missile structures: The information found in this book has been selected to convey an appreciation of the problems which face the missile structural design specialist and to provide a basis for understanding the considerations which lead to the final configuration. Since a complete outline of the theory and practice of the structural design and analysis cannot be included in a single volume, the more elementary considerations have been omitted. Design considerations, some of the problems facing the ballistic missile design engineer presented and various possible ways are discussed.

Design Report Ballistic Missile Defense Submarine SSBMD: This report published by the Ocean Engineering Design Project AOE 4066 (Spring 2008 Virginia Tech Team1). This concept design was completed in a two semester ship design course at Virginia Polytechnic Institute and State University. This paper also explains the Concept and Development of a Ballistic Missile Defense Submarine in SSBMD for the United States Navy. Initial Capabilities Document (ICD) and Virginia Tech SSBMD Acquisition Decision Memorandum (ADM). The submarine addresses the need to provide a sea-based ballistic missile defense launch capability to guard against rogue and hostile nation missile attack. littoral and open ocean environments. The primary threats expected to be encountered include operating in areas of dense contact with high levels of civilian vessels present (near international shipping lanes). The primary missions carried out by the submarine are Ballistic Missile.

\section{PROBLEM DEFINITION}

In this paper we designed and Analyzed a Subsonic Cruise missile which has a capable of carrying maximum load of $1500 \mathrm{kgs}$. The missile has turbofan engine and is equipped with a fins which are used for the direction control. Assumed that missile forward cg is at and aft $\mathrm{cg}$ is at and it has a length of 6 $\mathrm{m}$. The above are the design requirements to fulfill the CAD geometry[4]. This will be exported to ANSYS Workbench to calculate flow variations, stress strain relations and thermal variations[5].
Table 1: Design requirements

\begin{tabular}{|l|l|l|}
\hline Parameter & Value & Units \\
\hline Altitude range & $0-1000$ & Ft. \\
\hline Mach number & 0.8 & - \\
\hline Maximum Weight & $1000-1500$ & $\mathrm{~kg}$ \\
\hline Range & $1000-1500$ & $\mathrm{~km}$ \\
\hline Length & 6 & $\mathrm{~m}$ \\
\hline Diameter & 0.52 & $\mathrm{~m}$ \\
\hline Wing Span & 2.84 & $\mathrm{~m}$ \\
\hline
\end{tabular}

\section{AERODYNAMICS OF WING AND FIN}

From the case studies of cruise missiles like "NIRBHAY, BGM-109 TOMAHAWK, AGM-86ALCM, AGM129ACM, BABUR" has found that the length to diameter ratio is approximately $1: 11$. From the above analysis we have taken the length as $6.032 \mathrm{~m}$ and diameter as $0.52 \mathrm{~m}$. Coming to the aerodynamics part we have taken the wing planform from the mentioned references as "An-12 cub aircraft, C-130 hercules, C-160 transall tactical transport aircraft". The wing planform is back tapered leading edge with straight trailing edge which helps in lifting the heavy weights and also reduce the drag and increases the performance .[6]

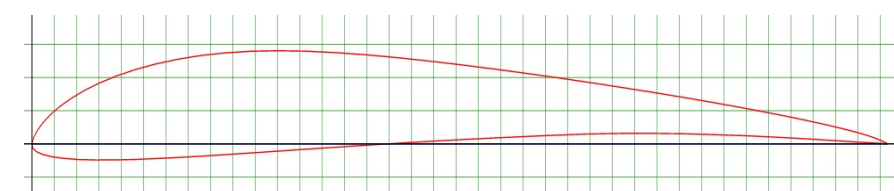

Figure 2. Airfoil shape

wing generates lift at any desired angle of attack and speed and the magnitude(velocity) do not go more than the total drag on the wing. Lift-to-drag( L/D) ratio should be high for subsonic speeds and vice versa for higher speeds and these can be found by flight test or from wind tunnel calculations. [7]. Thinnest airfoil (figure.2)produce high lift and reduces the drag on the wing. Airfoil Polar and Performances explains the nature of airfoil and shown in figure. 3

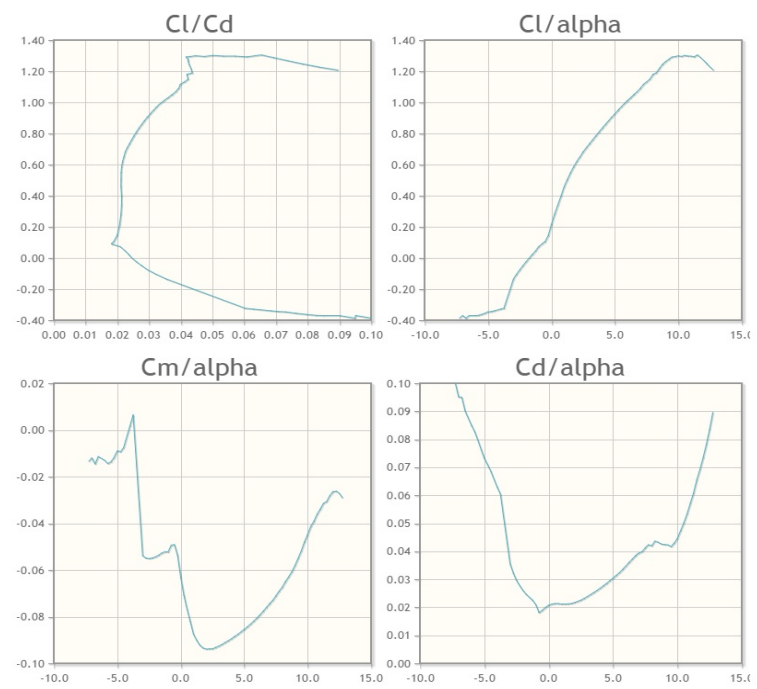

Figure 3. Airfoil Polar and Performances 
Fin is a member that attached to the structure. Fins ordinarily province as foils and also responsible for producing aerodynamic forces(lift). It has capacity to steer or stabilize the motion when travelling in the fluid(air,water) medium. Fins are accustomed to increase in exterior area for transferring the heat .Nomenclature of fins is explained in figure 4.

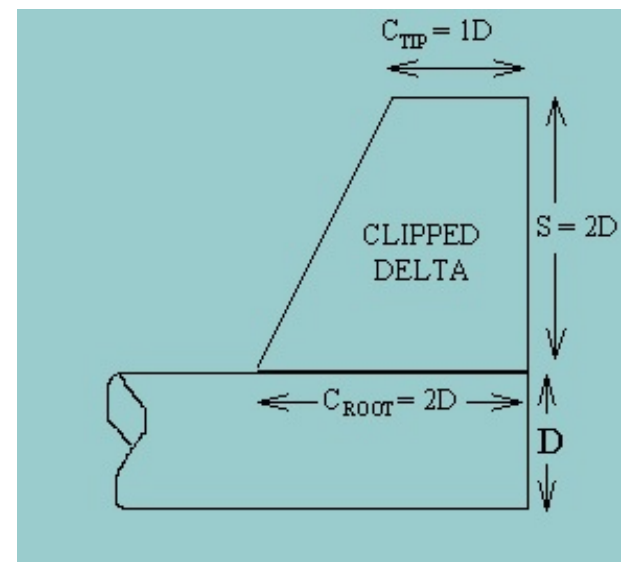

Figure 4. Nomenclature of fin

The fin requires the radial taper because the fin's chord length varies across the fin semi-span. Specifically, the fin's tip to root thickness would be equal to fin's tip to root chord length for any airfoil. To avoid the radial taper we need the fin plan form whose chord length is constant over the full semi span of the fin. It has been found that what's optimum at subsonic varies with what's optimum ay super sonic. The clipped delta planform sets an example for optimum planform for model rockets at subsonic speeds, and it varies to summetrical trapezoid for supersonic speeds. [8] and figure. 5 shows the symmetrical airfoil(NACA-0010) using for fin in this project[9][10].

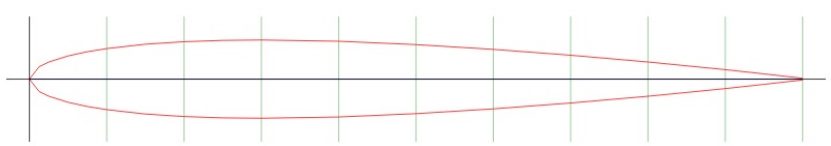

Figure 5. Symmetrical airfoil

\section{MODELING AND ANALYSIS}

For modeling we use CATIA V5 R20 version and for analysis ANSYS 14.5. Bottom-up assembly is used for doing model in CATIA

\section{Step 1: Starting CATIA V5}

Select new mechanical part design from the main bar. Select front plane.

\section{Step 2: Designing 2D model}

Select a spline tool and draw a cross section of missile.

\section{Step 3: converting the model from 2D to 3D}

By using shaft option, we need to revolve to the 360 degrees by selecting horizontal axis.

Then save and exit.

\subsection{Design of Wing}

\section{Step 1: Starting CATIA V5}

Select start mechanical design part design from the main bar. Select XY plane

\section{Step 2: Designing 2D model}

Import the coordinates for airfoil from excel sheet.

\section{Step 3: Designing 3D model}

By using pad option, we can get wing.

\subsection{Assembly Design}

From the product menu using existing components get all the required parts. Afterwards use the constraining tools like coincidence and offset which will be placed in exact position in mid section of a missile body. After completion of all the steps mentioned above, the final model is shown in figure 6 .

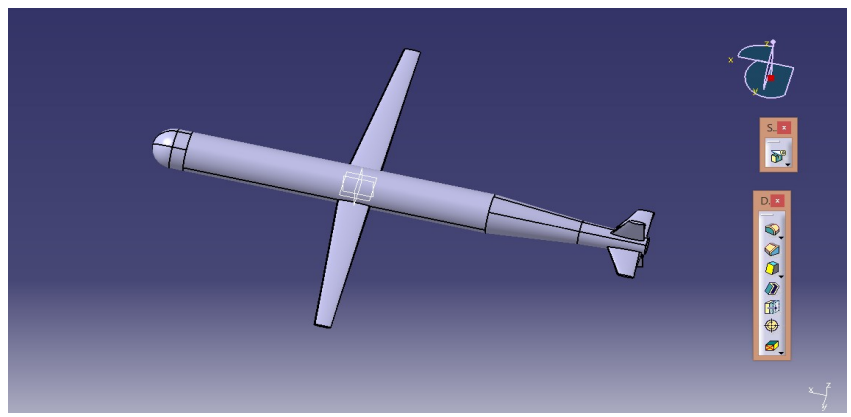

Figure 6. Assembly part of missile.

\subsection{Flow Analysis}

In this ANSYS work bench we are going to find the flow variation for the cruise missile designed in CATIA V5. While performing the flow analysis we get the meshed model as shown in the fig.7. Before entering the solution phase boundary conditions are required as shown below.

Inlet as velocity inlet -> click edit -> give velocity as $350 \mathrm{~m} / \mathrm{s}$ $>$ click ok.

Outlet as pressure outlet- $>$ click ok.

Missile wall has no slip conditions.

Domain wall as specified shear (this u can see in edit option).

Reference values -> compute from -> select inlet

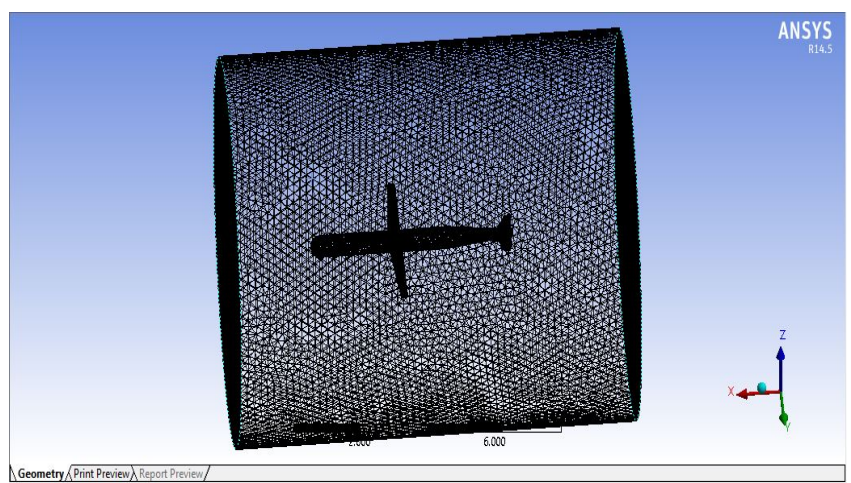

Figure 7: Mesh in wireframe 
When it is happened the reference values are come which your given in boundary conditions.

Solution -> solution methods -> formulation -> select implicit $>$ flux type as Roe-fds -> gradient as least square cell based $>$ flow as LUD(linear upwind differencing) -> Eddy viscosity modified as LUD.

If you want more accurate values click -> monitors $>$ residuals,print , plot $->$ give the values as in order of $10^{\wedge}-6->$ click ok.

Solution controls-> give courant number as less than 1

Solution initialization- $>$ Compute from: inlet- $>$ Initialize.

Run calculations -> give iterations as 1000 -> click on calculate.

\section{RESULTS}

From above calculations we get the following results.By seeing the figures 8,9,10 we found that dangerous(red)areas are very less which tells us this model is sustainable to the taken inlet conditions.

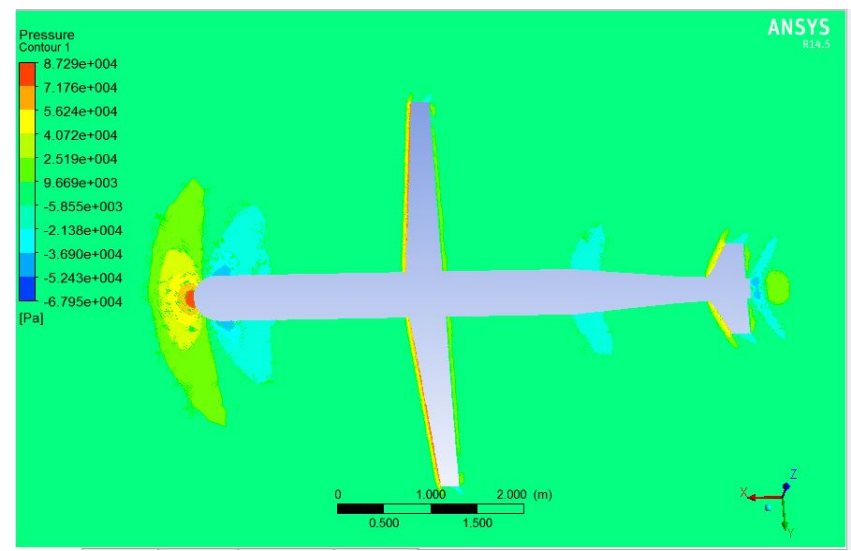

Figure 8: Pressure distribution

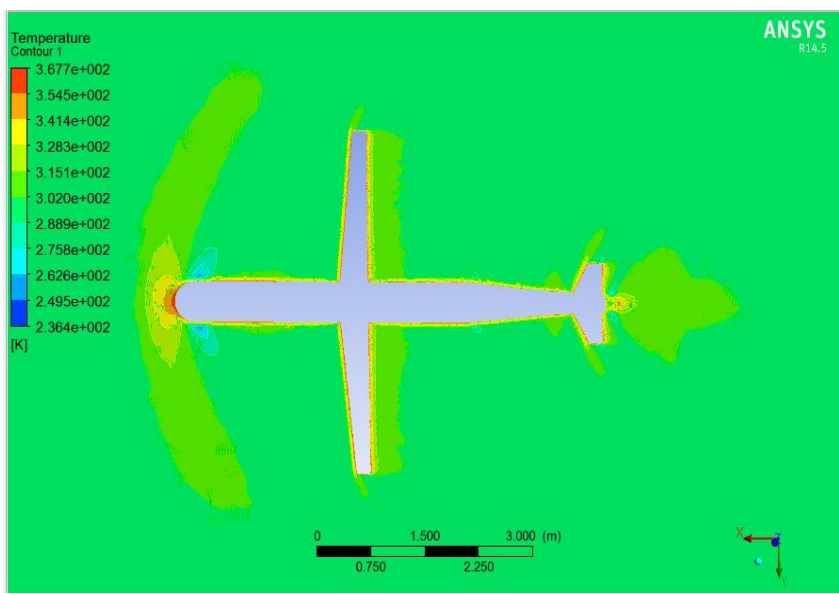

Figure 9: Temperature distribution

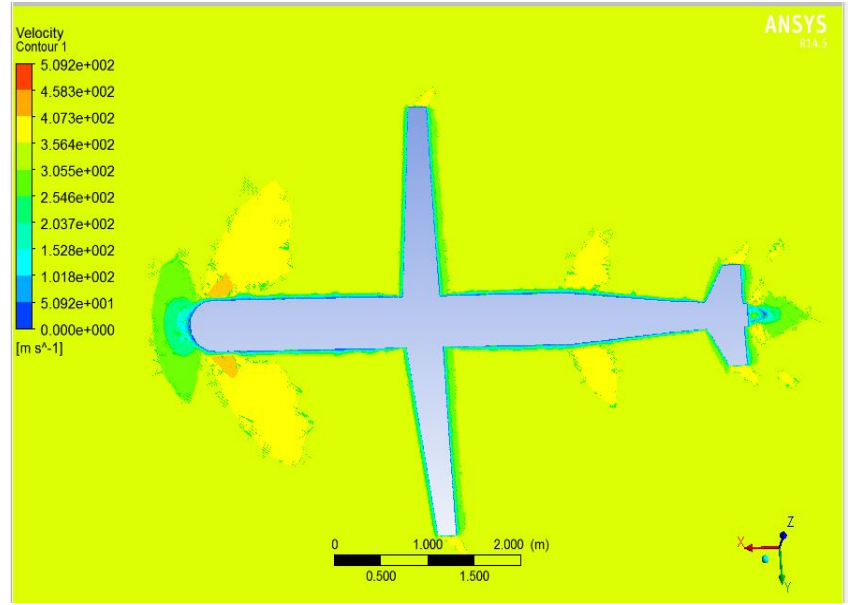

Figure 10: Velocity variation

\section{CONCLUSIONS}

We found that our designed model finds a smooth flow over it without disturbing any of the stimulated sub parts. This gives us to understand how missiles are been first conceptualized to design. Further we can introduce serial of further analysis detail for producing much accurate indigenous missile.

\section{FUTURE SCOPE}

Cruise missiles are developing in all elevation of their performance, and that continuing the growth rate in many domains of the world. Domains are doing work for the Department of Defense to chase the system constructs, technology developments, and proof-of-concept demonstrations that are required to maintain the preeminent position in the world. The United States holds in low observable air defense and low-observable air vehicles. Improving the radar and tracking technology devices programs will provide the legacy for detection and tracking of cruise missiles. The optimization of the dimensions and design considerations can produce effective analysis results.

\section{REFERENCES}

[1] J.B. Billingsley, "Ground Clutter Measurements for Surface- Sited Radar," Technical Report 786 Rev. 1, Lincoln Laboratory (1 Feb. 1993), DTIC \#AD-A262472.

[2]J.B. Billingsley, Low-Angle Radar Land Clutter: Measurements and Empirical Models (William Andrew/SciTech Publishing,Norwich, N.Y., to be published in fall of 2001).

[3] S. Ayasli, "SEKE: A Computer Model for Low Altitude Propagation over Irregular Terrain," IEEE Trans. AntennasPropag. 34 (8), 1986, pp. 1013-1023.

[4] C.W. Davis III, "The Airborne Seeker Test Bed," Linc. Lab. J. 3 (2), 1990, pp. 203-224.

[5] B.D. Carlson, L.M. Goodham, J. Austin, M.W. Ganz, and L.O. Upton, "An Ultralow-Sidelobe Adaptive Array Antenna," Linc. Lab. J. 3 (2), 1990, pp. 291-310.

[6]The Spitfire Wing Planform: A Suggestion J. A. D. Ackroyd Former Aerospace Division, Manchester School of Engineering, The Victoria University of ManchesterManchester, UK. 
[7] MISSILE AERODYNAMICS JACK N. NIELSEN CHIEF SCIENTIS; NASA AMES RESEARCH CENTER MOF' FIELD, CALIFO1NIA,Formerly President, Nielsen Engineering \& Research, Inc.Mountain View, California Originally published 1960 by McGraw-Hill Book Company, Inc. Reprinted 1988 by EAR, Inc.

[8]Missile Confguration Design textbook by S.S.CHIN,Chief AERODYNAMICS ENGINEER.

[9] "Meet India's New Nuclear Cruise Missile". The Diplomat. October 18, 2014.

[10]"Successfull test for India's Nirbhay cruise missile". Space Daily. Oct 21, 2014.

\section{BIOGRAPHIES}

${ }^{1}$ M.Ganesh, Asst Proffesor,Dept. of Aeronautical Engineering, MLRIT college, Telangana, India.

${ }^{2}$ Ch.Nandini, Student, Dept. of Aeronautical Engineering, MLRIT college, Telangana, India.

${ }^{3}$ M.Rakesh Reddy, Student, Dept. of Aeronautical Engineering, MLRIT college, Telangana, India.

${ }^{4}$ B.Siva Kumar, Student, Dept. of Aeronautical Engineering, MLRIT college, Telangana, India.

${ }^{5}$ M.Chaitanya, Student, Dept. of Aeronautical Engineering, MLRIT college, Telangana, India. 